\title{
ESPORTE DE ALTO RENDIMENTO: produção social da modernidade - o caso do vôlei de praia
}

\author{
Marília Maciel Costa*
}

\begin{abstract}
Resumo: O estudo, inicialmente, apresenta a inserção do esporte nos tempos modernos com o objetivo de resgatar e discutir a estruturação da produção do esporte de alto rendimento no Brasil. A modalidade vôlei de praia serviu de modelo empírico e procurou-se verificar, durante o levantamento dos dados coletados, a forma e os valores que predominavam no ambiente social em que se desenvolvia essa modalidade. Para isso, foram focalizadas as relações que se processavam no decorrer de sua estruturação e procurou-se verificar o grau de influência que elas sofreram diante das mudanças estruturais capitalistas e de novas situações conjunturais. Concluiu-se que o vôlei de praia brasileiro, na verdade, mesmo apresentando problemas inerentes à própria condição de esporte de alto rendimento, e diante das muitas adversidades que enfrenta no cenário social nacional, tem ocorrido com base nos valores ditados pelo "profissionalismo", suplantando os valores de uma cultura "amadorística" e tradicional, predominante no universo esportivo nacional.
\end{abstract}

Palavras-chave: vôlei de praia, esporte de alto rendimento, profissionalismo.

\section{Introdução}

O processo da gênese do esporte moderno e as mudanças por que passa o processo - de ethos amador para profissional - refletem mudanças sociais estruturais globais, cuja análise foi objeto de

\footnotetext{
* Mestre em Relações Internacionais e doutora em Sociologia do Esporte pela UnB; analista judiciária no TRF-1 ${ }^{a}$ Região. E-mail: amarelia@hotmail.com
}

Artigo recebido em 13 mar. 2006 e aprovado em 17 jul. 2006. 
estudo do cientista social Norbert Elias. Dentro do modelo teórico construído por Elias (1994), o esporte moderno surge no estágio de civilização em que as sociedades encontram-se pacificadas, em que a vida demanda um controle completo e uniforme de todos os impulsos instintivos vulcânicos, um controle permanente das emoções.

O conceito de "configuração social" desenvolvido por Elias serviu neste estudo como instrumento conceitual básico na análise das relações que formam, entre os principais atores deste universo social, o esporte de alto rendimento, em particular o vôlei de praia brasileiro. Há no conceito de "configuração social" a exata noção de que está no dinamismo das relações sociais o germe das mutações sociais; valioso, portanto, para a compreensão da passagem do ethos amador para o profissional.

Tendo em vista o conceito de configuração, o campo esportivo do vôlei de praia é analisado como aquele constituído por pessoas que estão orientadas umas para as outras e unidas das mais diversas maneiras, cujas relações refletem os diferentes potenciais de poder exercidos nesses contatos. Essas pessoas, por sua vez, são movidas por valores que se formam e se transformam no próprio decorrer do contato entre elas. Há, dessa forma, no universo esportivo estudado, uma teia de relações humanas em constante mutação que respondem pela formação do próprio campo, ou seja, os agentes do campo do vôlei de praia formam um grupo social que se relaciona tanto com grupos internos quanto com externos ao campo e é dentro desse universo que acontecem os entrelaçamentos dos atos, das necessidades, das idéias e dos impulsos, dando origem à dinâmica de funcionamento do campo.

Como referencial teórico, portanto, a caracterização do esporte moderno, apresentada por Elias, auxiliou na tarefa de identificar os principais traços da dinâmica de funcionamento do vôlei de praia brasileiro. O "ethos profissional", nomeado pelo autor como a tendência do esporte moderno, permitiu-nos identificar valores que apontam para a construção de uma realidade social próxima da do 
vôlei de praia brasileiro, que será o dado empírico escolhido pela pesquisa para o acesso às condições sociais da modernidade.

No Brasil, o vôlei de praia tornou-se um esporte de alto rendimento bem-sucedido. Tem apresentado, há mais de uma década, os melhores resultados do mundo. De modo geral, a investigação revelou a existência de uma organização no vôlei de praia sob base gerencial destoante do contexto nacional esportivo, uma vez que este tem sido vítima de falências de confederações e federações, envolvimento com atos fraudulentos de dirigentes, falta de seriedade na condução financeira das organizações esportivas, legislações falhas e falta de continuidade no trabalho. Diante disso, surgiu a principal indagação da pesquisa: Que fatores são responsáveis pelo quadro hegemônico do vôlei de praia, destoante do cenário esportivo nacional?

Em busca da resposta, a pesquisa pretendeu levantar a configuração social $^{1}$ do vôlei de praia no período de 1986 a 2004, quando passou a se destacar no cenário esportivo nacional e internacional.

O estudo mostrou que a estruturação desse esporte é sustentada por um processo de institucionalização singular, responsável pela profissionalização e pelos expressivos resultados da modalidade, garantindo-lhe posição hegemônica. Por "processo de institucionalização do vôlei de praia" compreendem-se os acontecimentos que permitiram à Confederação Nacional de Voleibol do Brasil (CBV) reivindicar, a partir de 1986, para si, o monopólio da organização e da estruturação da prática do vôlei de praia no território nacional, contribuindo para que fossem estabelecidas as regras de funcionamento da modalidade. Daí a importância de se estabelecer o entendimento do que constitui o processo de institucionalização em relação ao fenômeno estudado.

A atual estrutura profissional do vôlei de praia no Brasil faz parte de uma realidade recente, resultado do abandono dos valores 
"amadorísticos", predominantes em suas primeiras exibições nacionais, que datam de 1947. O levantamento histórico desse período mostrou um vôlei de praia estava organizado sob a égide do amadorismo. Não havia uma instituição central que respondesse pelo comando da modalidade e pela organização dos eventos, e, além disso, os recursos financeiros eram escassos, impossibilitando dedicação exclusiva dos jogadores, que não recebiam ajuda pecuniária nem treinamento específico.

A partir do processo de institucionalização em 1986, com a reivindicação do monopólio da estruturação do esporte no País pela Confederação Brasileira de Voleibol (CBV), o vôlei de praia tomou o rumo do profissionalismo. Com tal propósito, em 1989, a Confederação criou, em sua estrutura organizacional, um departamento para tratar especificamente do vôlei de praia, com staff exclusivo. Confeccionou-se um manual de funcionamento do voleibol de praia brasileiro, com regras para orientar a prática do esportem, e uma forma séria e comprometida de atuação passou a predominar.

Teóricos que falam da modernidade, como Giddens, Debord e Castells, forneceram para a pesquisa uma leitura atualizada das transformações e mudanças que traçam o perfil de novas conexões sociais. A formação e funcionamento do esporte de alto rendimento encontra seu lócus originário no que Giddens (2002, p. 221) chamou de "alta modernidade" ou "modernidade tardia", para muitos pósmodernidade.

A "modernidade", para efeitos da pesquisa, é considerada em termos institucionais e seu conceito parte da premissa de que as mudanças e transformações sociais introduzidas pela modernidade se entrelaçam de maneira direta com a vida individual. Assim, "modernidade" implica a presença de 
instituições que diferem de todas as formas anteriores de ordem social quanto a seu dinamismo, ao grau em que interferem com hábitos e costumes tradicionais e o seu impacto global. $\mathrm{O}$ ritmo da mudança social é muito mais rápido que em sistemas anteriores, não só o ritmo da mudança social, mas a amplitude e profundidade que afetam as práticas sociais. (Giddens, 2002, p. 21).

A "alta modernidade" ou "modernidade tardia" corresponderia, então, à presente fase de desenvolvimento das instituições marcadas pela radicalização e pela globalização dos traços da modernidade. $\mathrm{O}$ traço distintivo entre a modernidade e a "alta modernidade" encontra-se no deslocamento da produção de manufatura de bens materiais para a da informação. Castells (2001) chamou a época atual de "era da informação", mostrando que a expansão das instituições modernas está fortemente marcada pelo imenso fluxo de informações que as avançadas formas de comunicação têm propiciado.

A radical mudança na relação entre espaço e tempo, conectando mundos nunca antes imagináveis, proveniente da revolução tecnológica ocorrida nos meios de comunicação (impulsionada pelo desejo de expansão do capital), provocou uma gama de alterações nas relações sociais. Foi essa recente configuração social que Debord (1994) chamou de "sociedade do espetáculo", cuja crítica principal é a passividade com que esta absorve a informação, permitindo aos donos da informação o controle sobre a massa.

A forma de organização e os resultados apresentados pelo vôlei de praia brasileiro têm permitido a identificação de valores, práticas, idéias e traços que o caracterizam como um esporte da modernidade, inserido nos princípios que regem o ethos profissional (Elias, Dunning, 1985). Esse esporte é marcado pela maciça presença de competitividade, pela orientação cada vez maior para resultados, pela presença de regras bem definidas, pela organização centralizada 
capaz de gerir um crescente número de funções que se acumulam na prática do esporte, pela presença de valores pecuniários em todos os níveis de relacionamento e pela atenção especial ao espectador.

\section{Esporte-espetáculo: uma leitura do nosso tempo}

Nas relações construídas dentro do espaço ${ }^{2}$ esportivo atual de alta competitividade, percebe-se que os elementos racional, mercadológico e espetacular (apresentação teatral) tornam-se cada vez mais presentes, responsabilizando-se, assim, por parte substancial da dinâmica das relações do campo esportivo.

O esporte de alta competitividade é o esporte-espetáculo de rendimento transformado em mercadoria. Desporto de rendimento é, pois, aquele que tem o âmago de sua atividade centrada na finalidade de obter resultados, o que equivale a dizer obter resultados provenientes dos mais altos rendimentos. Nesse caso, o objetivo do esporte de alto rendimento converge para os recordes e as vitórias, consubstanciando a idéia de que esporte é rendimento.

Guttmann (2004) apresenta, no contexto atual da sociologia do esporte, reflexões sociológicas marcantes para melhor percebermos como o esporte moderno se apresenta na sociedade atual. $\mathrm{O}$ autor enfatiza as muitas facetas que diferenciam o esporte moderno do esporte dos séculos anteriores e apresenta a cumplicidade desse fenômeno com a forma contemporânea da vida. Considera como principais características do esporte moderno a secularização, a igualdade de oportunidades de competição (no sentido de que as condições de competir são as mesmas para todos, teoricamente), a especialização de papéis, a racionalização, a organização burocrática, a quantificação e a questão dos recordes. ${ }^{3}$

Para o Guttmann, a idéia do record, traduzida pela busca da performance atlética, quantificada com exatidão matemática, acon- 
tece sob uma base organizacional burocrática e forte especialização de funções. Dentro de uma análise crítica, o autor mostra o surgimento do fenômeno do record associado ao forte desejo e crença na idéia do progresso linear. Resulta, pois, segundo o autor, da combinação do impulso de quantificar com o desejo de ganhar, de se exceder, de ser o melhor.

A legislação brasileira ${ }^{4}$ conceitua desporto de rendimento como sendo aquele praticado segundo normas e regras nacionais e internacionais, com a finalidade de obter resultados e integrar pessoas e comunidades do País e estas com outras nações. Dentro do conceito de desporto de rendimento, a legislação fez distinção entre o organizado nos moldes profissional e não-profissional. $\mathrm{O}$ modo profissional é caracterizado por remuneração pactuada por contrato de trabalho ou demais formas contratuais pertinentes. $\mathrm{O}$ "profissional" é considerado pela lei como aquele que se torna um empregado de uma entidade esportiva, com direitos e deveres de um empregado qualquer que se capacita para o desempenho de sua função.

A legislação, ao tratar do desporto de rendimento praticado de forma não-profissional, apresenta a questão da idade do atleta. $\mathrm{O}$ atleta não-profissional que pratica esporte de alto rendimento é aquele impossibilitado legalmente, por causa da idade, de assinar contrato de trabalho - não pode ter idade inferior a 14 nem superior a 18 anos. Essa categoria admite a existência de incentivos materiais que não caracterizem remuneração derivada de contrato de trabalho ou até mesmo a inexistência de qualquer forma de remuneração ou de incentivos materiais. $\mathrm{O}$ exemplo mais típico é o da categoria de base do esporte de alto rendimento, que comporta jogadores com pouca idade.

Registrado o que a legislação brasileira considera um esporte de alto rendimento, a presente pesquisa adotou como esporte de 
alto rendimento o conceito apresentado acima, mas não seguiu os parâmetros distintivos entre o que é considerado atleta profissional e não-profissional, que no caso da lei, conforme visto, restringe-se à idade do atleta para assinar um compromisso de trabalho. A pesquisa adotou o termo "profissional" no sentido sociológico explorado por Elias $^{5}$ e por outros sociólogos contemporâneos que apresentaram estudos valiosos do esporte na modernidade, como Bourdieu e Giddens. ${ }^{6}$

O esporte de alto rendimento está associado a grandes espetáculos ligados à dimensão econômica, impulsionado pela revolução tecnológica da "era da informação" na "alta modernidade". A dinâmica de funcionamento do esporte de alto rendimento levanta questões inerentes à modernidade e corresponde a formas institucionais nela presentes, em conjunto com o seu universo de fragmentação e dispersão. O estudo do fenômeno esportivo nos permite levantar as conexões entre a Sociologia e as instituições modernas.

A leitura da sociedade feita por Debord, ${ }^{7}$ em que reinam as modernas condições de produção que se apresentam como acumulações de espetáculos, auxilia na compreensão da expressão mais recente do esporte do nosso tempo, o esporte-espetáculo. $\mathrm{O}$ show esportivo vende e se converte em mercadoria.

O esporte-espetáculo seria, pois, o esporte profissional de alta competitividade transformado em mercadoria, ou seja, o esporte, como mercadoria, é apresentado de forma espetacular com vistas a alcançar maior valor-de-troca. A questão mercadológica na sociedade capitalista encontrou no espetáculo uma forma de expandir o esporte. Afinal, explorar a forma espetacular de apresentação tornou-se um produto social da modernidade. $\mathrm{O}$ caráter espetacular da vida moderna passou a impregnar todas as esferas de relacionamento humano e o esporte, em particular, adequou-se de forma patente. 
A forte tendência dos últimos anos do século XX de o esporte transformar-se em mercadoria remete-nos aos estudos de Marx (1975), nos quais o autor esclarece como a mercadoria ganha papel preponderante no modo de produção capitalista. Marx alerta para a realidade do valor da mercadoria que se expressa pela totalidade de suas relações sociais. E assevera:

A mercadoria é misteriosa simplesmente por encobrir as características sociais do próprio trabalho dos homens, apresentando-as como características materiais e propriedades sociais inerentes aos produtos do trabalho, por ocultar, portanto, a relação social entre os trabalhadores individuais dos portadores do trabalho total, ao refleti-la como relação social existente, à margem deles, entre os produtos de seu próprio trabalho. Através dessa simulação, os produtos do trabalho se tornam mercadorias, coisas sociais, com propriedades perceptíveis e imperceptíveis aos sentidos. (Marx, 1975, p. 81).

E é partindo dessa ótica que Marx levanta a questão do duplo caráter do valor da mercadoria, ou seja, o valor-de-uso e o valor-de-troca, princípio importante para compreender o esporte como mercadoria. $\mathrm{O}$ valor-de-uso estaria relacionado à utilidade da mercadoria em satisfazer necessidades humanas, enquanto o valor-de-troca pressupõe a contraposição de outra mercadoria como equivalente. Assim, no contexto das relações capitalistas de produção, a conversão do esporte profissional em mercadoria resulta da objetivação do valor-de-uso do jogo esportivo transformado em valor-de-troca.

Sob o signo da mercadoria, os meios de comunicação potencializam o esporte de forma espetaculosa, para que, assim, como mercadoria, seja impulsionada sua equivalência (valor-detroca) e possa, portanto, servir aos interesses expansionistas do capital.

Em que condições histórico-sociais a mercadoria assumiria papel predominante na sociedade e em que momento o esporte 
assumiria papel de destaque como mercadoria? O desenvolvimento das forças produtivas modificou as condições de existência dos grupos humanos. Partindo da pura condição de sobrevivência no interior de uma economia natural de produção artesanal, as mudanças no processo produtivo proporcionaram o excedente em relação à sobrevivência. Nesse estágio, intensificou-se o comércio, criando condições para o acúmulo de capitais.

A mercadoria assumiria, pois, o domínio da economia nas condições econômicas e sociais do que denominamos de mercantilismo. Continuaria a imperar com a Revolução Industrial, quando o trabalho humano também foi transformado em mercadoria, surgindo a figura do assalariado.

Mas, até então, em tal contexto social, o homem jamais era considerado em seus lazeres. O lazer só veio a se tornar mercadoria no final do século XX.

As mudanças no processo produtivo continuaram a se processar, adquirindo os contornos atuais nas últimas décadas do século $\mathrm{XX}$. $\mathrm{O}$ processo de reestruturação capitalista traduziu-se por mudanças na fonte de produção, acarretando transformações profundas nas relações entre economia, estado e sociedade, caracterizando o que Castells (2001, p. 26) chamou de "capitalismo informacional", que significa "atributo de uma forma especifica de organização social em que a geração, o processamento e a transmissão da informação tornam-se as fontes fundamentais de produtividade e poder devido às novas condições tecnológicas surgidas nesse periodo histórico".

As conseqüências foram sentidas nas várias esferas da relação humana com profundas mudanças manifestadas nas relações de trabalho, na percepção de tempo e nas várias formas de expressões. O tempo social na era da automação permitiu o desenvolvimento de relações de trabalho não mais baseadas na necessidade de sobrevivência, mas, sobretudo, na de lazer, impulsionando o 
desenvolvimento da indústria do divertimento. $\mathrm{O}$ esporte passou a ser um dos grandes triunfos da indústria do lazer. ${ }^{8}$

O lazer, tendo no esporte um grande representante, tornouse, então, fator de destaque para a vida pós-moderna. $\mathrm{O}$ advento da automação no processo de produção levou à diminuição do tempo de trabalho social, necessário na escala da sociedade, dando espaço para o surgimento de novas formas de ocupação da força de trabalho.

A sociedade que emerge no final do século XX é uma sociedade caracterizada por uma revolução tecnológica sem precedentes na história da humanidade, tamanha a rapidez de fluxo entre informações, capital e comunicação cultural. Ficou conhecida também como a "era da globalização" - o termo diz respeito ao sentido de alcance global do capital adquirido, tendo em vista a expansão da informação do conhecimento do último quartel do século XX, proporcionada pela revolução tecnológica da informação.

Para conectar os mercados de cada país, a capacidade de informação tornou-se crucial e a solução foi investir maciçamente na tecnologia de informação. Com isso, desenvolveram-se e ampliaram-se as condições de comunicação, provenientes da tecnologia desenvolvida nas áreas de microeletrônica, computação, telecomunicações, radiodifusão e optoeletrônica.

$\mathrm{Na}$ "alta modernidade", a mercadoria participa intensamente das relações sociais, de modo que tanto o "vivido" como o "nãovivido" transformam-se em mercadoria. Alimentadas pela linguagem do espetáculo, as necessidades pós-modernas são ininterruptamente criadas e recriadas de forma a expandir o mercado para o consumo das mercadorias. $\mathrm{O}$ fenômeno esportivo amolda-se com rapidez à nova realidade.

A comunicação espetacular na era da informação brota da organização social e invade o cotidiano das pessoas de forma que, 
na sociedade pós-moderna, o consumo extrapola a necessidade, transformando-se em um dever para o homem que se vê cego pela vitrine da aparência, conforme afirmou Debord (1994). O que presenciamos na sociedade de consumo pós-moderna é a venda autenticando o valor.

O espetáculo e todas as suas formas particulares - informação ou propaganda, publicidade ou consumo direto de divertimentos - são uma força ativa e como tal evocam na conseqüências práticas. Críticas à supervalorização da imagem têm apontado para uma realidade que tem contribuído para uma vida mais contemplativa do que ativa, o que afasta as pessoas da realidade, induzindo-as ao conformismo, reverenciando o status quo.

A "pós-modernidade" com seu discurso global do espetáculo é conveniente aos donos da informação, os quais têm o poder de selecionar o que deve ser comunicado. Os indivíduos contemporâneos, ao se tornarem cada vez mais suscetíveis aos imperativos da rentabilidade, criaram um ambiente propício para que a mídia os submetesse aos seus valores - o que o espetáculo deixa de falar, deixa de existir para o espectador e o que é enfatizado por ele passa a ser a realidade do espectador, adquirindo o peso indiscutível de prova histórica. Cumpre destacar, nesse sentido, que o movimento de inovação tecnológica, responsável pela expansão estrondosa dos meios de comunicação neste final de século, reforçou ainda mais a autoridade espetacular na sociedade capitalista.

Nesse contexto, como se explica a posição do esporte de alto rendimento em relação ao poder do espetáculo na sociedade pós-moderna, marcada pela era da informação? O forte apelo da sociedade do espetáculo é a imagem, que, por sua vez, constitui a porta sensitiva do esporte para alcançar o público. O "ver" das "apresentações" abre a íntima relação entre o esporte e as emoções, canal de penetração direto entre os agentes envolvidos. A forma 
espetacular de apresentação passou a ser essencial para a dinâmica de funcionamento do esporte profissional de alto rendimento e presenciá-lo tornou-se um hábito no cotidiano das pessoas.

$\mathrm{Na}$ economia em expansão dos serviços e dos lazeres, o esporte é uma espécie de mercadoria espetacular que aparece entre os artigos que promovem a modernização das vendas pelo capitalismo. Percebe-se cada vez mais a utilização do discurso embasado na imagem e impulsionado pela tecnologia da informação (Castells, 2001). A partir da década de 70, a indústria do espetáculo - a televisão, o cinema e as atividades editoriais - tem explorado maciçamente o esporte em seu poder de exibição.

$\mathrm{O}$ esporte serve à linguagem reinante, constitui uma das respostas a este momento social, condizente com uma sociedade espectadora e consumidora. Mostra-se com poder de convocação e capacidade de penetração social. A demanda por esporte cresce tanto para assistir a ele (enquadra-se perfeitamente no modo de vida contemplativa da sociedade moderna), quanto para praticá-lo (combate às más conseqüências físicas da vida contemplativa).

De que maneira se processa a exploração do esporte como força criadora de valores e de novas necessidades para bem servir a indústria do consumo na alta modernidade? A forma espetacular de apresentação dos fenômenos esportivos constitui um agente criador de significados e, portanto, de necessidades, que são traduzidas em mercadoria de consumo num ambiente tecnológico altamente desenvolvido - a era da informação.

O espetáculo esportivo tem a capacidade de produzir novas práticas movidas pela criação de novos valores. No universo esportivo, a primazia da aparência é um fato, demonstrada pela aptidão para mostrar habilidades físicas, as quais envolvem o corpo, que é a principal ferramenta de trabalho do desportista, objeto totalmente visível. ${ }^{10}$ 
As habilidades físicas são trabalhadas e desenvolvidas por grupos de especialistas que buscam desenvolver movimentos ascendentes para uma exposição das habilidades corporais sob a base da simulação, e é nesse sentido que o esporte constitui, nas palavras de Wacquant (2002), "arte social".

A importância do aspecto mimético dos feitos esportivos foi levantada primeiramente pelo cientista social Norbert Elias, ${ }^{11}$ mas é na era da automação, no mundo global, que ganhou força de penetração social nunca antes experimentado. O termo "mimético" foi apresentado pelo autor para expressar o aspecto imaginário que a prática esportiva propicia ao suscitar os sentimentos de medo e tensão sem estarem relacionados a acontecimentos da vida real.

A atividade esportiva, assim, possibilitou ao ser humano um grau de tensão e excitamento que o tirou de uma rotina cotidiana da sociedade moderna e o lançou em momentos de êxtase "controlado". Os feitos esportivos são uma forma segura de vivenciar emoções controladas que, ao se associarem aos visuais espetaculosos (proporcionados pelo avanço tecnológico), criam uma fórmula atrativa para o homem de vida contemplativa do século XXI. Os jogos esportivos passaram a ser a expressão social da liberação contida das emoções, possibilitando que se experimentasse "mimeticamente" viver fortes emoções de uma forma refinada, permitindo tanto ao praticante quanto a quem assiste, o gozo.

O valor que a sociedade pós-moderna consagra ao esporte tem sido ampliado por estruturas de patrocínio e marketing esportivo. É um trabalho direcionado, com ênfase cada vez maior no consumo que o visual induz. Estruturas de patrocínio e marketing esportivo foram criadas para explorar a imagem, motivar comportamentos e criar necessidades consumistas.

O marketing esportivo é uma nova área de estudo que surge visando potencializar o esporte enquanto um grande veículo de 
comunicação do século, tornando-o cada vez mais espetacular e, conseqüentemente, rentável, ou seja, o marketing esportivo traz à tona o poder de comunicação do esporte, atribuindo-lhe a condição de mercadoria rentável. Melo Neto (2003) conceitua marketing esportivo como um conjunto de ações de comunicação com vistas à valorização de um produto no mercado.

Como estratégia de investimento, as ações de marketing promocional têm expressado o aspecto mercadológico do esporte de alto rendimento. Por meio das ações de marketing promocional, as empresas associam sua imagem ao esporte, buscando, num primeiro momento, uma imagem forte, consolidada e positiva, peculiar aos feitos esportivos, para, em seguida, aumentar suas vendas, veiculando sua marca na mídia e, conseqüentemente, conquistando novos clientes e mercados. Como estratégia de marketing, surge a figura do patrocínio, que

constitui uma estratégia de ação de 'marketing' promocional que, ao dar suporte às demais ações de marketing promocional, contribui para o alcance dos objetivos estratégicos de marketing da empresa, em especial no que se refere à imagem corporativa, promoção da marca, posicionamento do produto, promoção de vendas e comunicação com cliente, fornecedores, distribuidores e demais parceiros. (Melo Neto, 2003, p. 14).

A empresa patrocinadora tem sido, nestas últimas décadas, o grande investidor do esporte de alto rendimento, superando o Estado. É dela que têm surgido os recursos financeiros para custear as despesas de promoção e de realização de eventos esportivos e daí o interesse em promover verdadeiros espetáculos de grande apelo atrativo.

O patrocínio representa uma estratégia a mais para conquistar o mercado. Além das estratégias tradicionais - produtos e serviços de qualidade com preços competitivos -, as empresas procuram valorizar suas marcas, obter credibilidade e, sobretudo, visibilidade, interagindo com o cliente em potencial. 
As práticas esportivas no universo do alto rendimento têm refletido o profundo processo de reorganização do tempo e do espaço que a modernidade tem apresentado. $\mathrm{O}$ desenvolvimento da mídia impressa e eletrônica fez com que os acontecimentos distantes tivessem influência nos eventos mais próximos, de forma que experiências canalizadas pela comunicação pudessem influenciar na organização das relações sociais. ${ }^{12}$

A busca pela expansão do capital é um ponto comum dessas explicações teóricas, da qual o fenômeno esportivo não escapa. A tendência crescente do esporte de rendimento à racionalização, à "espetacularização" e à "mercantilização" é um fato.

Weber (1994) demonstrou em estudo teórico, intitulado teoria da "ação social", como a sociedade moderna tende à ação calculada, permitindo visualizar o esporte de alto rendimento dentro desta tendência. Weber observou que o fato produtor do capitalismo foi a contabilidade racional do capital e que esta seria a norma mestra a guiar as instituições modernas. O desporto moderno, como instituição moderna, segue, portanto, o princípio da racionalização e o esporte de alto rendimento, mais ainda, em razão da instrumentalização racional, utilizada para se alcançar novos mercados.

Enfim, o esporte de alto rendimento traz inscrito as condições sociais da modernidade - constrói-se socialmente num ambiente marcado pela racionalização e pela globalização, no sentido do alcance global do capital adquirido por meio da expansão da informação do conhecimento do último quartel do século XX, proporcionada pela revolução tecnológica da informação (cf. Castells, 2001, p. 87).

Para levantar a configuração social do universo estudado, houve contribuição teórica valiosa dos conceitos trabalhados por Bourdieu (1990) de "campo social", "espaço social", "habitus", "estilo de vida", na medida em que seus estudos sobre a representação abstrata das relações de poder presente nas diversas esferas de 
atuação humana forneceram subsídio para identificá-las no campo esportivo do vôlei de praia.

Os estudos de Bourdieu nos auxiliaram a identificar os agentes e seus respectivos papéis nas relações de poder que se desenvolvem no campo, não perdendo de vista o(s) capital(is) social(is) que legitimam a posição dos diversos agentes no campo.

A CBV, importante agente no campo de estudo do vôlei de praia brasileiro, atuou na organização do esporte no País e também no exterior. Outros importantes agentes do campo foram identificados: o patrocinador Banco do Brasil, as federações, as empresas de marketing e os atletas.

A CBV foi presidida por Carlos Arthur Nuzman de 1975 a 1995, portanto, foi ele o presidente no momento da institucionalização da modalidade. Ocupou também o cargo de presidente do Conselho de Vôlei de Praia da Federação Internacional de Voleibol (FIVB). Contribuiu para a formação do Circuito Mundial de Vôlei de Praia, em 1989, e para a inclusão do esporte no programa dos jogos olímpicos, em 1993, com a primeira exibição em 1996. Fechou com o Banco do Brasil patrocínio para a modalidade, representando o suporte financeiro que faltava, o que viabilizou a criação do Circuito Nacional de Duplas de Vôlei de Praia.

Ary Graça, presidente atual (2005), assumiu a presidência da Confederarão em 1997, dando continuidade à ocupação de vários postos de cunho deliberativo dentro das instituições internacionais de peso no esporte. Tem levado a CBV a gerenciar o esporte cada vez mais como um empreendimento.

Como, então, o vôlei de praia brasileiro se insere no contexto esportivo da "alta modernidade" ou "modernidade tardia"? O vôlei de praia, sob a gerência da CBV, passou a ser administrado como "negócio" e os "eventos esportivos" passaram a ser considerados 
os principais produtos de venda. O espaço social do vôlei de praia brasileiro passou, portanto, a revelar forte influência do aspecto mercadológico, característica marcante da sociedade de consumo atual.

A investigação procurou justamente perceber como a $\mathrm{CBV}$, na condição de instituição gerente do vôlei de praia no País, introduziu a modalidade neste novo paradigma do esporte profissional, associando investimento financeiro maciço, estrutura organizacional nos moldes empresariais e competições de alto nível técnico.

O estudo da dinâmica de funcionamento do principal evento nacional do vôlei de praia no Brasil, o Circuito Nacional de Duplas de Vôlei de Praia, permitiu visualizar as características da estrutura profissional que passaram a predominar no esporte no País. O Circuito Nacional, patrocinado pelo Banco do Brasil, foi operacionalizado junto às federações com vistas aos objetivos mercadológicos por meio de ações como a criação de uma eficiente estrutura de marketing e comunicação; valorização do evento por meio da participação de atletas e equipes de alto nível; escolha de diferentes localidades do País para exibição dos eventos, potencializando a conquista de novos clientes para o Banco do Brasil e, ao mesmo tempo, popularizando o esporte no território nacional; formação de um ranking nacional e de um calendário que permitissem aos atletas de vôlei de praia competir nos principais torneios nacionais e internacionais, bem como mantê-los em forma durante todo o ano.

Contextualizar o vôlei de praia perante os acontecimentos nacionais e internacionais revelou em que circunstância social foi possível ser montada uma estrutura de êxito para o esporte no País.

O contrato de patrocínio entre a CBV e o Banco do Brasil, para que este financiasse o vôlei brasileiro, incluindo o Circuito Nacional de Duplas de Vôlei de Praia, ocorreu devido a uma política estratégica geral do Banco para se livrar da crise financeira 
que enfrentava, desencadeada após perder a condição de autoridade monetária. O Banco estava para sofrer uma crise institucional, caso não implementasse uma política para atrair clientes, de preferência mais jovens. Havia necessidade de renovar sua imagem, rejuvenescendo-a. A política de marketing esportivo foi uma das muitas medidas adotadas pelo Banco à época.

O sucesso das experiências da CBV de utilizar verbas de patrocínio para financiar seus times de quadra na década de 80 contribuiu para que a mesma política fosse implementada pela Confederação em relação ao vôlei de praia. Ademais, as pesquisas de base do departamento de marketing do Banco apontavam também o vôlei de praia como o esporte de preferência do jovem no Brasil.

A viabilização de uma política de patrocínio no esporte teve a contribuição da conjuntura nacional - o fim da ditadura militar. $\mathrm{O}$ fato possibilitou que fosse contemplada legalmente a questão do esporte no meio empresarial: a Lei Zico (1993) inaugurou a jornada, seguida pela Lei Pelé (1998) e, depois, a Lei Piva (2001).

Quanto à conjuntura externa, o fim da Guerra Fria - com conseqüente afastamento dos governos nacionais nos empreendimentos financeiros esportivos - favoreceu a injeção de capital empresarial nos esportes. $O$ grande potencial de representatividade do esporte deixou de ser arma publicitária utilizada pelos governos durante a Guerra Fria para ser arma publicitária para o mundo empresarial.

\section{A condução do vôlei de praia brasileiro nos moldes da "cultura profissional"}

Ao concluir, a investigação não registrou práticas arcaicas e paternalistas na condução da modalidade que comprometessem seu desempenho. A permanência de valores paternalistas dentro 
uma cultura esportiva nacional e de resquícios de regras arcaicas na legislação esportiva brasileira não comprometeu, até os dias de hoje, o bom desempenho do vôlei de praia.

Um exemplo disso é o remanescente arcaísmo da proibição legal de remuneração dos dirigentes das Confederações e Federações, o que favorece a presença de uma política de corrupção no esporte brasileiro. Trabalhar sem pagamento, explicou Azevedo (1999), pode resultar em favoritismos, criando, assim, ambiente para a corrupção de vantagens econômicas, e mostrou que o futebol tem sido vítima de tal estrutura. Como a questão se processa na prática do vôlei de praia?

Antes, cabe ressaltar que a referência ao termo "estrutura arcaica e paternalista" na condução esportiva remete, no presente trabalho, ao modo de condução do esporte centrado no favoritismo, em que os interesses pessoais suplantam os interesses em prol do desenvolvimento auto-sustentável da modalidade. "Amadorismo" não está sendo empregado como sinônimo de "estrutura arcaica e paternalista", mas, sim, como um resquício da estrutura societária anterior à da modernidade que, quando mantido na estrutura profissional atual, contribui para o aparecimento e a manutenção de “estruturas arcaicas e paternalistas". O termo "amador" está sendo empregado sociologicamente, conforme teorizou Elias.

Importante também observar o fato de o vôlei de praia ter se apoiado em valores predominantemente tidos como profissionais não nos permite inferir que não há relações de favoritismo no campo esportivo do vôlei de praia e que as distorções de comportamento não possam ocorrer.

O que realmente se pode constatar é que não se verificam denúncias de mau uso do dinheiro, ocasionando endividamentos e encargos para a modalidade, a ponto de comprometer sua inserção no mundo do esporte profissional. 
Cabe ainda salientar que tais considerações não excluem o prestígio social e até mesmo político que a direção de um esporte nacional confere a qualquer dirigente e que isso possa, por si só, ser o principal motivo que leve uma pessoa a se dedicar a tal atividade.

Assim, a pesquisa percebeu, no caso específico do vôlei de praia, que os interesses por status ou prestígio pessoal, sustentados ou não pelo idealismo, não constituem por si só entraves a uma orientação embasada em princípios administrativos e financeiros racionais.

Verifica-se, tanto na prática quanto no discurso dos dirigentes da condução do vôlei de praia, que, com ou sem remuneração, a fonte do prestígio para o campo provém do orgulho de conduzirem o esporte nos moldes empresariais, o que contribui para sedimentar a "cultura do profissionalismo" (no sentido sociológico apresentado por Elias), respaldada pela competência administrativa.

Faz-se fundamental entender que o significado de "competência" que o campo estudado assimilou respalda-se no conhecimento, na visão estratégica e na transparência financeira, com vistas a promover um negócio que gere lucro. Esse fator representa um dos pontos-chave para compreender o bem-sucedido desempenho da modalidade.

Status e prestígio são buscados em fontes opostas ao comando dos dirigentes que se guiam pela "cultura do amadorismo". Assim, encontra-se uma das explicações para os resultados hegemônicos da modalidade. Explicativo é o estudo de Lever (1983), ao fazer comentários sobre os problemas de funcionamento do futebol no Brasil com relação à condução do esporte. Lever salientou que a principal diferença entre os dirigentes do futebol brasileiro e os proprietários de times esportivos das principias corporações do esporte mundial não estaria no objetivo, mas na orientação financeira e na responsabilidade. A assimilação de uma conduta profissional estaria moldada dentro disso. 
Nesse sentido, a pesquisa verificou que houve, no vôlei de praia brasileiro, assimilação de uma conduta "profissional" com base empresarial, em que foi observada a valorização da competência. ${ }^{13}$ Predominou no vôlei de praia o interesse pela transformação do esporte em mercadoria. A falta de ética, comumente presente na condução dos esportes no País - entendida como sendo algumas práticas que se materializam pela manipulação em prol de interesses pessoais, troca de favores, suborno e corrupção, que contaminam a "cultura do profissionalismo" a ponto de descaracterizá-la - não encontrou campo fértil no vôlei de praia.

Mas, quais os aspectos que a pesquisa revelou terem contribuído para a adoção de uma condução profissional no vôlei de praia brasileiro? Primeiro, foi a questão da criação, no decorrer do processo de institucionalização, de um departamento específico para tratar do vôlei de praia dentro da CBV sob a base da independência financeira em relação à Confederação. Estabelecida como norma embrionária, instituiu-se a obrigação de o departamento estabelecer seu próprio auto-sustento, deixando na base de formação a lição mais básica do universo empresarial: a maximização do lucro depende dos aspectos inerentes à produtividade, ou seja, se há produção e qualidade, há, conseqüentemente, ganhos. Assim, o próprio staff preocupa-se em trabalhar com "competência", pois a sobrevivência do departamento dependeria diretamente do desempenho dos funcionários, além de estes representarem um grupo de profissionais que estariam preocupados em adquirir conhecimento específico para desempenharem tarefas específicas dentro do departamento.

Outro aspecto que a pesquisa revelou ter contribuído para a adoção de uma condução profissional foi a presença de forte divisão de funções no funcionamento da modalidade, facilitado por um comando único. 
Sob o ponto de vista da "cultura profissional", o modelo de um comando único tem possibilitado maior agilidade no processo de decisões, enquanto a terceirização tem possibilitado à CBV um quadro administrativo mais enxuto, com menos gastos financeiros, ostentando uma folha de pagamento menos onerosa. Ao delegar funções, sempre sob o seu comando, a CBV pôde contratar serviços de especialistas; reforçar o aspecto de profissionais capacitados, sem, contudo, assumir diretamente um grande e oneroso grupo de profissionais especializados e, ainda, garantir menor grau de personalização nas relações, afastando a figura paternalista do comando.

O patrocínio constitui outro aspecto importante a ser analisado. A política de patrocínio é que garante o sustento financeiro da modalidade. Logo, nos primórdios da institucionalização do vôlei de praia, houve uma concentração de esforços para que se fechassem contratos de patrocínio com empresas. Nesse sentido, importante é salientar os pontos em que o sistema de patrocínio implantado no vôlei de praia contribuiu para a sedimentação de uma estrutura profissional. A política de patrocínio está muito ligada à questão da "imagem eficiente"; assim, elementos tais como conhecimento, visão estratégica, transparência financeira e ética - característicos do quesito competência nos moldes profissionais - são supervalorizados e sua presença define se vale a pena patrocinar ou não aquele esporte.

A maneira como é estabelecida a composição de duplas marca outro ponto a favor da não proliferação de estruturas arcaicas dentro da modalidade. Os atletas são responsáveis diretos e únicos pela composição de seus próprios times - as duplas. Eles são quem decide, e não a $\mathrm{CBV}$, desde questões relacionadas à preparação técnica - como, quando e com quem treinar - até aquelas que dizem respeito ao sustento financeiro da dupla, como negociações com patrocinadores, colaboradores e outros. O fato proporciona aos 
jogadores um contato mais direto com a realidade que circunda a prática do esporte, provocando uma tomada de consciência acerca de sua condição no processo. Ao tomarem a frente das negociações, em detrimento dos dirigentes, os atletas adquirem maior noção de seus próprios direitos, passando a agir de forma mais independente, não esperando por "favores" nem por atitudes paternalistas. São estabelecidas obrigações para eles e isso leva-os a manter compromissos e responsabilidades próprias, sem as conduções paternalistas da instituição.

Há também os aspectos vistos sob o prisma das relações no campo estudado: De que forma essas relações que se processam no campo estudado contribuem para a manutenção de uma estrutura considerada profissional para a modalidade? Como tem ocorrido a absorção dos valores do ethos profissional na condução da modalidade?

O modelo implantado pela CBV estabeleceu um compromisso da Confederação diretamente ligado à estrutura organizacional dos eventos e não diretamente à figura do atleta. Segundo seus dirigentes, o compromisso da $\mathrm{CBV}$ é fornecer torneios com eventos estruturados para que o atleta possa se projetar e conseguir, dessa forma, o patrocínio para seu próprio sustento financeiro como atleta. Assim, a CBV se exime das burocracias administrativas e financeiras que estariam atreladas aos compromissos empregatícios com o atleta - o que no esporte de alto rendimento pode representar grandes salários e, portanto, um peso em termos financeiros - portanto, diminui as despesas de funcionamento e, ao mesmo tempo, concebe maior desembaraço à máquina administrativa. $\mathrm{O}$ modelo acaba por reforçar a relação de "impessoalidade" entre a instituição e o atleta, fato característico do ethos profissional. A figura de uma instituição paternalista é totalmente afastada, nesse caso. 
A CBV, ao mesmo tempo, mantém poder de polícia sobre os atletas, no que diz respeito a exigir obrigatoriedade do registro na Confederação, bem como de o atleta ter que pedir permissão para representar o País no exterior e de impor-lhe punições, em caso de descumprimento das normas. Isso possibilita a ela estar em constante guarda sobre o "negócio vôlei de praia", predominando, pois, na relação entre a instituição e o atleta, o oposto do que podemos chamar de uma relação paternalista, na medida em que há um controle sobre a prática do atleta por meio das obrigações estipuladas a ele e cujo descumprimento o exclui do sistema.

No que diz respeito à relação da $\mathrm{CBV}$ com o patrocinador Banco do Brasil, deve-se chamar a atenção para o aspecto normativo e contratual e para a reciprocidade de interesses. Patrocínio é investimento e não benevolência, traduz-se pelo interesse do capital em ganhar mercado. Importa ressaltar que essas são predominantemente relações de "negócio".

No âmbito de análise das relações entre a CBV e as promotoras (geralmente empresas de marketing), também se confirmou um modelo favorável à implantação da cultura profissional. A promotora dos eventos esportivos é a maior expressão de terceirização do campo e a maneira como se processou no vôlei de praia garantiu uma das bases da implantação de um modelo profissional.

Não é só a simples terceirização dos serviços que garante o modelo profissional, mas também a forma como ocorre, ou seja, o estabelecimento claro e preciso do papel de cada um no processo e a exigência da CBV por "excelência" no serviço apresentado. Como profissionais especializados que são, as promotoras são contratadas pela CBV para executar o serviço em que são especializadas. 
Em todo esse processo, o estreito comprometimento entre as federações estaduais e a Confederação no trabalho de sedimentação do monopólio institucional representou um reforço na implantação da cultura profissional dentro do campo esportivo estudado.

As federações estão espalhadas pelos Estados e constituem as representantes institucionais da Confederação. As federações têm dentro de suas atribuições a tarefa de buscar junto ao governo local apoio de infra-estrutura aos eventos, o que facilita para a CBV a condução nacional da modalidade, já que, a princípio, as federações se encontram mais próximas da realidade local, portanto, mais aptas a estabelecerem os contatos necessários. A obrigatoriedade se estende ao fato de as federações terem que dar satisfação de todo o processo à $\mathrm{CBV}$, apresentado, a cada evento, minuciosos relatórios, o que é uma garantia de manutenção da qualidade dos eventos. Há, também, o fato de que a CBV tem nas federações a garantia de continuidade do trabalho, já que um Brasil que guarda grandes distâncias geográficas requer mais olhares.

Enfim, o processo de institucionalização do vôlei de praia levou-o ao encontro da abertura comercial, da mobilização crescente de capitais e das atividades empresariais do mundo globalizado. A organização dirigente provocou uma profunda reestruturação empresarial, através da adoção cada vez maior da informatização, de forma a viabilizar esse esporte conforme as demandas da pósmodernidade.

O processo de institucionalização do vôlei de praia associouo às questões de mudanças tecnológicas e organizacionais voltadas para o constante aumento da produtividade e para os interesses da mídia, garantindo-lhe sintonia com os rumos da pós-modernidade. Esse processo levou em conta a necessidade de promover e mobilizar alternativas excitantes à solidão e à passividade do espectador. 


\section{Notas}

1 "Configuração social" no sentido usado pelo cientista social Norbert Elias (1994a), de arranjo social, dando a idéia da pluralidade de pessoas interconectadas de maneira dinâmica, formando verdadeiras teias. Segundo o pesquisador, existe a necessidade de se criar conceitos que melhor traduzam a riqueza de vivência social. Elias trouxe para a sociologia, entre outros, os termos sociogênese e configuração social, procurando fazer com que o conceito expressasse o próprio processo. A teoria da "configuração social" será importante para a pesquisa e será apresentada com maiores detalhes à frente.

2 No texto, o termo tem a mesma conotação empregada pelo sociólogo Bourdieu (op. cit), em seus estudos relacionados à sociologia da cultura, ou seja, uma representação abstrata do lugar de existência cotidiana com suas múltiplas relações, onde estão inseridos os "campos", que constituem os espaços de luta pelo controle de um capital específico que garante sua legitimidade. Assim, podemos denominar campo político, econômico, esportivo etc.

3 Para uma análise conceitual e crítica do significado social de recorde e suas possíveis conseqüências para o esporte, ver Guttmann (2004).

4 Aqui, faz-se referência à Lei Piva (Lei $\mathrm{n}^{\circ} 10.264$, de 16 de julho de 2001), em vigor atualmente.

5 A teoria elisiana que caracteriza o ethos profissional em comparação com o ethos amador foi apresentada por Elias e Dunning (1985). A obra apresenta o esporte como prática diante dos valores que caracterizam o ethos amador e/ou profissional.

6 A tese de mestrado apresentada por Anthony Giddens, em 1961, na London School of Economics, tratou da Sociologia do Esporte.

7 Debord (1994, p. 14) desenvolve uma teoria crítica sobre o tema, cuja idéia central é a de que "o espetáculo não é um conjunto de imagens, mas uma relação entre pessoas, mediada por imagens". Para o autor, o espetáculo está presente em todas as esferas de relacionamento da sociedade moderna e é responsável pelo estado de alienação em que ela se encontra. 
8 O crescimento do interesse pelo esporte pode ser constatado, na prática, pela proliferação de clubes e ligas milionárias, surgidas na segunda metade do século XX no mundo do esporte. Por exemplo, a Liga Nacional de Basquete Americana, conhecida por NBA (National Basketball Association), uma das mais rentáveis associações esportivas do mundo, lucrou, em 1994, por equipe, em média, cerca de 5,9 milhões de dólares por ano (Sirotsky \& Associados, 4 mai. 1999, p. 65). A Liga Nacional de Hockey norte-americana, a NHL (National Hockey League), a exemplo da liga de basquete profissional dos Estados Unidos, a NBA, apresenta base financeira espetacular; as franquias obtiveram, em média, 5,5 milhões de dólares de lucro no período de 1994-1995 (p. 72). No futebol profissional europeu, encontram-se as três ligas mais ricas da modalidade, a Prime League, na Inglaterra, a Liga Principal, na Espanha, e a Série "A", na Itália).

9 Cabe salientar que discussão teórica concernente a esse período histórico-econômico-social procura apontar diferenças conceituais entre o que se classifica por "economia global" e "economia mundial". Segundo Fernand Braudel (1967) e Immanuel Wallerstein (1974), economia mundial é uma economia em que a acumulação de capital avança por todo o mundo, existe no Ocidente, no mínimo, desde o séc XVI. Uma economia global é algo diferente: é uma economia com capacidade de funcionar como uma unidade em tempo real, em escala planetária. Para Castells (2001), embora o modo capitalista de produção seja caracterizado por sua expansão contínua, sempre tentando superar limites temporais e espaciais, foi apenas no final do séc XX que a economia mundial conseguiu tornar-se verdadeiramente global, com base na nova infra-estrutura, propiciada pelas tecnologias de informação e de comunicação. Essa globalidade envolve os principais processos e elementos do sistema econômico e é nas redes de informação que conectam os centros empresariais que as verdadeiras operações de capital ocorrem (Castells, 2001, p. 111). Outros teóricos fazem distinção do termo "mundial" e "global" por acreditarem que o conceito "global" pode levar ao equívoco de que exista a inclusão de todos no processo ou uma homogenização entre países, o que serviria para mascarar desigualdades de poder e riqueza entre grupos sociais e países, como levantou Chesnais (1994, p. 206-48). O autor explica que o 
sistema global está acontecendo pela primeira vez na história, o capital é gerenciado vinte e quatro horas por dia em mercados financeiros globalmente integrados, funcionando em tempo real. Para o presente trabalho, o termo "globalização" interessa enquanto conseqüência da modernidade. O termo corresponde a mudanças estruturais sociais profundas, concorrendo para uma supervalorização do fenômeno esportivo.

10 Bourdieu desenvolveu estudos que buscaram investigar, dentro da lógica da distinção social, os valores que os grupos sociais possuíam para nortear a seleção no universo de possibilidades das práticas esportivas. $\mathrm{O}$ corpo ganhou posição de destaque nas investigações do sociólogo. Ele o reconhece como um grande signo distintivo. Por ser o corpo uma dimensão privilegiada do habitus, a relação instrumental com o próprio corpo funciona como parâmetro para a escolha da prática esportiva. Significa dizer que a lógica de adoção de determinado esporte é compreensível se se levar em conta a relação com o próprio corpo, que por sua vez está inscrita no habitus - gerador do "estilo de vida". A sua visão é que nós aprendemos pelo corpo e que a ordem social se inscreve no corpo. Para Bourdieu, o corpo é altamente perceptível dos signos de que é portador, ou seja, o corpo carrega uma fisionomia social, deixando transparecer a estrutura do espaço social. As propriedades corporais são apreendidas por meio dos sistemas sociais, tendo em vista todas as diferenças de condições sociais. O corpo é visto, portanto, como um produto social. Para maiores detalhes, ver o capítulo 3 de $L a$ distinción: criterios y bases sociales del gusto (1988), onde Bourdieu dedicou atenção especial à prática esportiva.

11 Os estudos desenvolvidos por Elias (Elias e Dunning, 1985) que tratam da gênese do esporte moderno mencionam a força da representatividade do esporte, apontando o papel do aspecto "mimético" na convocação das emoções. Numa perspectiva histórica ontogenética, os estudos mostraram como o esporte passou, na sociedade moderna, a representar uma canalização da agressividade tão latente em épocas históricas anteriores do desenvolvimento social dos homens. Com a figura do cavaleiro na Idade Média e mais tarde com os reis guerreiros, os momentos de pilhagem, guerra, caça a homens e animais eram 
corriqueiros na estrutura da sociedade. A liberação das emoções no cotidiano da vida desses homens foi colocada sob um controle social cada vez mais rígido, amparado pelo surgimento do Estado Moderno. A prática do esporte foi a resposta da sociedade moderna ao forte estágio de controle das emoções, latente numa sociedade cujo Estado tinha o "dever" de proteger, dando condições de criar nos indivíduos hábitos mais pacíficos.

12 Nas palavras de Giddens (2002, p. 31): “As imagens visuais criam texturas de experiência via mídia que não estão disponíveis na palavra impressa".

$13 \mathrm{O}$ termo competência deve ser entendido, neste contexto, como a capacidade de emprego de meios que levem ao fim almejado.

High performance sports: a social production of modernity - the beach volleyball model

Abstract: The study examines sports in modern times. The objective of this was to retrieve and discuss the structuring of high performance sports production in Brazil. Beach volleyball served as a model. During the data collection process, aim was made to ascertain the forms and values that are predominant in the social environment of beach volleyball. For this, focus was placed on the relationships that developed during the structuring process and attempt was made to verify how such relationships were influenced by the capitalist-structural changes and the new settings that resulted therefrom. The study concluded that despite having problems that are inherent to the sport's being highly performance-oriented, and in light of many adversities faced in the national scenario, Brazilian beach volleyball is based on the values dictated by professionalism that overcome values of the amateur-like and traditional culture that are predominant in the universe of national sports.

Key-words: beach volleyball, high performance sport, professionalism. 


\section{Referências bibliográficas}

ALMEIDA, Cândido José Mendes de; SOUZA, Madalena Mendes de Almeida; LEITÃO, Sérgio Sá (Orgs). Marketing esportivo ao vivo. Rio de Janeiro: Imago, 2000.

ARON, Raymond. As etapas do pensamento sociológico. São Paulo: Martins Fontes, 1999.

ASSUNÇÃO, Luiz Otávio Teles. O temp(l)o das Geraes: a nova ordem do futebol brasileiro - o estádio Governador Magalhães Pinto. Dissertação (Doutorado Sociologia) - Universidade de Brasília, Brasília, 2000.

AZEVEDO, Aldo Antonio de. Dos velhos aos novos "cartolas": uma interpretação do poder e das suas resistências nos clubes, face ao impacto das relações futebol-empresa. Dissertação (Doutorado em Sociologia) - Universidade de Brasília, Brasília, 1999.

BANCO DO BRASIL. Diretoria de Marketing e Comunicação. Gerência de Promoção de Vendas. Marketing Esportivo - Projeto Vôlei Brasil, TênisBrasil e Paradesporto Brasil. Brasília, 2003/0090. (Paper).

. A grande sacada: como rejuvenescer uma imagem de 184 anos. 1992.

. Esporte e cultura. Apresenta informações sobre a atuação do Banco do Brasil nas políticas de patrocínio do esporte no Brasil. Disponível em: $<$ http://www.bb.com.br $>$. Acesso em: 10 set. 2003 e 8 set. 2004.

BAUER, Martin W.; GASKELL, George. Pesquisa qualitativa com texto, imagem e som: um manual prático. Rio de Janeiro: Editora Vozes, 2003.

BOURDIEU, Pierre. Como se pode ser esportivo? In: BOURDIEU, Pierre, Questões de Sociologia. Rio de Janeiro: Marco Zero, 1983. . As regras da arte. São Paulo: Companhia das Letras, 1996. 
BOURDIEU, Pierre. La distinción: criterios y bases sociales del gusto. Madri: Taurus, 1998. . Sociología y cultura. México: Consejo Nacional para la Cultura y las Artes, 1990.

. Economia das trocas simbólicas. São Paulo: Editora Perspectiva, 1992.

BRASIL. Lei n. 8.672, de 6 de julho de 1993. Institui normas gerais sobre desportos e da outras providências. Disponível em: $<\mathrm{http} / / \mathrm{www}$. inacionunes.com.br/int_leizico.html>. Acesso em: 7 out. 2004.

BRASIL. Ministério da Educação e do Desporto. Instituto Nacional de Desenvolvimento do Desporto. Desporto adaptado no Brasil: origem, institucionalização e atualidade. Brasília: Indesp, 1998. (Série Esportes para Pessoas Portadoras de Deficiência).

. Formação das seleções básicas no voleibol brasileiro. Brasília: Indesp, 1998. (Série Ciências dos Esportes).

BRAUDEL, Fernand. Civilisation matérielle et capitalisme: XV-XVII siécle. Paris: Armand Colin, 1967.

CASTELLS, Manuel. A sociedade em rede. 5 ed. São Paulo: Paz e Terra, 2001.

CHESNAIS, François. La mondialisation du capital. Paris: Syros, 1994.

COMITÊ OLÍMPICO BRASILEIRO. Apresenta informações sobre o $\mathrm{COB}$, a memória olímpica, o Brasil nos jogos olímpicos, as notícias e eventos relacionados às Olimpíadas. Disponível em : <www.cob. org.br>. Acesso em: 7 set. 2003.

CONFEDERAÇÃO BRASILEIRA DE VOLEIBOL. Estatuto 2004. Rio de Janeiro: CBV, 2004. . Manual de voleibol de praia 2004. Rio de Janeiro: CBV, 2004. 
. Seleções. Praia. Competições Nacionais. Viva Vôlei. Imprensa. Arbitragem. Institucional. Bate Bola. Apresenta diversas informações sobre a Confederação Nacional de Voleibol, aspectos institucionais, entrevistas com atletas e dirigentes e notícias atualizadas do vôlei de quadra e do vôlei de praia brasileiros no País e no exterior. Disponível em: <http://www.cbv.com.br $>$. Acessos em: 19, 20 e 25 ago. 2003; 4 e 29 set. 2003; 3, 4, 15 e 29 out 2003; 29 mar. 2004; 28 abr. 2004; 7 e 17 jun. 2004; 28 jul. 2004; 30 ago. 2004; 14, 22 e 27 set. 2004; 13 e 30 dez. 2004; 15 jan. 2005; 2 fev. 2005 e em 11 jul 2005.

COSTA, Marília Maciel. Vôlei de praia: configurações sociais de um esporte- espetáculo de alto rendimento no Brasil. Tese (Doutorado em Sociologia) - Universidade de Brasília, 2005.

DEBORD, Guy. The society of the spectacle. New York: Zone Books, 1994.

DOWBOR, Ladislau; IANNI, Octavio; RESENDE, Paulo Edgar A. (Orgs.) Desafios da globalização. Petrópolis (RJ): Vozes, 1997.

ELIAS, Norbert. A sociedade dos indivíduos. Rio de Janeiro: Jorge Zahar, 1994a.

. Introdução à Sociologia. Lisboa: Edição 70, 1999.

. O processo civilizador. Rio de Janeiro: Jorge Zahar, 1994b. v. 1 e 2 .

ELIAS, Norbert; DUNNING, Eric. A busca da excitação. Lisboa: Difel, 1985.

FEDERAÇÃO INTERNACIONAL DE VOLEIBOL (Suíça). Goodwill Games: Beach Volleyball Event Regulations. Goodwill Games Beach Volleyball Competition August 29 to September 4. Lausanne, 23 jul. 2001, p. 1-7.

GRAÇA, Ary. Administrando o vôlei como uma empresa. Case Studies, Revista Brasileira de Management, Rio de Janeiro, v. 6, n. 39, p. 52-60, jul./ago. 2003. 
GIDDENS, Anthony. Política, Sociologia e teoria social. São Paulo: Fundação Editora da UNESP, 1998.

. Capitalismo e moderna teoria social. São Paulo: Editora Presença, 2001.

. Modernidade e identidade. Rio de Janeiro: Jorge Zahar, 2002.

GUTTMANN, Allen. From ritual to record. New York: Columbia University Press, 2004.

HELAL, Ronaldo. O que é Sociologia do Esporte. São Paulo: Brasiliense, 1990.

KASZNAR, Istvan Karoly; GRAÇA, F. Ary S. O esporte como indústria: solução para criação de riqueza e emprego. Rio de Janeiro: Confederação Brasileira de Voleibol, 2002.

LEVER, Janet. A loucura do futebol. Tradução de A B. Pinheiro de Lemos. Rio de Janeiro: Record, 1983.

MARX, 1975, p. 81

MULLIN, Bernard J.; HARDY, Stephen; SUTTON, William A. Marketing esportivo. São Paulo: Artmed, 2004.

MELO NETO, Francisco Paulo de. Administração e marketing de clubes esportivos: a base para criação do clube-empresa. Rio de Janeiro, Sprint, 1998.

. Marketing de patrocínio. Rio de Janeiro: Sprint, 2003.

PAN-AMERICANO: Vôlei. Informativo da Confederação Brasileira de Voleibol, Rio de Janeiro, n. 6, p. 4. ago. 2003.

PARKS, Janet B.; ZANGER, Beverly K.; QUARTERMEN, Jerome. Contemporary sport management. Champaign, IL: Human Kinetics, 1998.

SILVA, José Fernando da; LIMA, Ricardo Barbosa de; ROSSO, Sadi Dal (Orgs.). Violência e trabalho no Brasil. Goiás: Editora UFG; Brasília: MNDH, 2001. (Série Violência em Manchete, v. 4). 
SIROTSKY \& ASSOCIADOS. O volleyball profissional no Brasil: uma oportunidade de venture capital. Parecer técnico encomendado pela Confederação Brasileira de Voleibol. Rio de Janeiro, 4 maio 1999.

TESTA, Antônio Flávio. Esporte, mercado e racionalização: o impacto da globalização e da tecnologia sobre a organização, a prática dos esportes e da cidadania à luz da Lei Pelé. Dissertação (Doutorado em Sociologia) - Universidade de Brasília, Brasília, 1999.

TUBINO, Manoel José Gomes. Dimensões sociais do esporte. São Paulo: Cortez, 1992.

WACQUANT, Loïc. Corpo e alma: notas etnográficas de um aprendiz. Rio de Janeiro: Relume Dumará, 2002.

WALLERSTEIN, Immanuel. The modern world system. Nova York: Academic Press, 1974.

WEBER, Max. Economia e sociedade: fundamentos da sociologia compreensiva. Trad. Regis Barbosa e Karen E. Barbosa. Brasília (DF): Ed. UnB, 1994.

. Ensaios de Sociologia. Rio de Janeiro: Zahar, 1974. 